\title{
Intracellular glutathione levels are involved in carbonyl cyanide p-(trifluoromethoxy) phenylhydrazone-induced apoptosis in As4.1 juxtaglomerular cells
}

\author{
YONG HWAN HAN and WOO HYUN PARK \\ Department of Physiology, Medical School, Institute of Medical Sciences, \\ Chonbuk National University, JeonJu 561-180, Republic of Korea
}

Received September 3, 2010; Accepted November 5, 2010

DOI: 10.3892/ijmm.2011.604

\begin{abstract}
Carbonyl cyanide p-(trifluoromethoxy) phenylhydrazone (FCCP) is an uncoupler of mitochondrial oxidative phosphorylation in eukaryotic cells. In the present study, we investigated the involvement of reactive oxygen species (ROS) and glutathione (GSH) in FCCP-induced As4.1 juxtaglomerular cell death. Intracellular ROS levels were decreased by FCCP at the early time points (10-150 min) and increased at $48 \mathrm{~h}$. FCCP inhibited the activity of Mnsuperoxide dismutase (Mn-SOD) via down-regulating its protein expression. Ebselen (an antioxidant) significantly attenuated ROS levels in FCCP-treated cells, but did not prevent FCCP-induced cell death. Moreover, intracellular GSH content was rapidly diminished within 10 min of FCCP treatment, which was accompanied by a reduction of the mitochondrial membrane potential [MMP $(\Delta \psi \mathrm{m})]$. Lbuthionine sulfoximine (BSO, a GSH synthesis inhibitor) significantly augmented As4.1 cell death by FCCP. However, N-acetylcysteine (NAC, a GSH precursor and antioxidant) attenuated GSH depletion, MMP $(\Delta \psi \mathrm{m})$ loss and cell death in FCCP-treated As4.1 cells. In addition, NAC
\end{abstract}

Correspondence to: Dr Woo Hyun Park, Department of Physiology, Medical School, Chonbuk National University, JeonJu 561-180, Republic of Korea

E-mail: parkwh71@jbnu.ac.kr

Abbreviations: FCCP, carbonyl cyanide p-(trifluoromethoxy) phenylhydrazone; ROS, reactive oxygen species; PARP, poly(ADPribose) polymerase; FBS, fetal bovine serum; MTT, 3-(4,5dimethylthiazol-2-yl)-2,5-diphenyltetrazolium bromide; PI, propidium iodide; PS, phosphatidylserine; FITC, fluorescein isothiocyanate; GSH, glutathione; CMFDA, 5-chloromethylfluorescein diacetate; NAC, N-acetylcysteine; BSO, L-buthionine sulfoximine; SOD, superoxide dismutase; Ebselen, 2-phenyl-1,2benzisoselenazol-3(2H)-one; DCF, 2,7-dichlorofluorescein; MMP $(\Delta \psi \mathrm{m})$, mitochondrial membrane potential; DNP, 2'4-dinitrophenol

Key words: FCCP, ROS, As4.1, GSH, mitochondrial membrane potential increased Mn-SOD activity and decreased ROS levels in FCCP-treated As4.1 cells. In conclusion, these results suggest that compared to ROS levels, intracellular GSH levels are more closely linked to FCCP-induced apoptosis in As4.1 juxtaglomerular cells.

\section{Introduction}

Juxtaglomerular cell tumors, first described in the late 1960s (1), are benign tumors of the kidney. Reninomas are understood to arise from juxtaglomerular cells. Clinically, the patients suffer from headaches, polyuria, nocturia and dizziness among other symptoms. As4.1 cells, a model for juxtaglomerular cells, were isolated from a kidney neoplasm of a transgenic mouse containing a renin SV40 T-antigen transgene (2). Although JGA cell tumors are considered benign, with only one report of metastasis, they are potentially lethal if left untreated (3).

Reactive oxygen species (ROS) include the hydrogen peroxide $\left(\mathrm{H}_{2} \mathrm{O}_{2}\right)$, the superoxide anion $\left(\mathrm{O}_{2}^{-}\right)$and the hydroxyl radical $\left({ }^{\circ} \mathrm{OH}\right)$. These molecules can regulate many important cellular functions such as transcription factor activation, gene expression, cell differentiation and proliferation (4). Principal antioxidant enzymes include superoxide dismutase (SOD), which is expressed as extracellular (EC-SOD), cytoplasmic $(\mathrm{Cu} / \mathrm{Zn}-\mathrm{SOD})$ and mitochondrial isoforms (Mn-SOD). These isoforms metabolize $\mathrm{O}_{2}^{-}$to $\mathrm{H}_{2} \mathrm{O}_{2}$. Further metabolism of $\mathrm{H}_{2} \mathrm{O}_{2}$ by catalase and glutathione (GSH) peroxidase yields $\mathrm{O}_{2}$ and $\mathrm{H}_{2} \mathrm{O}(5)$. GSH is a main non-protein and thiol antioxidant in the cell and is crucial for regulation of cell proliferation and cell signaling (6) and is known to protect cells from toxic insults through detoxification of toxic metabolites of drugs and scavenging ROS (7). In addition, alterations in its concentration have been demonstrated as a common feature of many pathological situations including cancer and neurodegenerative diseases (8). Moreover, high GSH levels have been associated with an apoptotic resistant phenotype in various cells (9).

Mitochondria are cellular organelles that perform pivotal functions essential for ATP production, ROS generation and metabolism. Mitochondria are also involved in cell death (or apoptosis) and cell survival pathways (10). Therefore, specific drugs that damage the mitochondria may provide a foundation 
to treat a variety of diseases, especially cancer, wherein these functions are deregulated. For instance, a mitochondria uncoupler can rapidly dissipate the gradient of protons across the inner mitochondrial membrane, trigger ROS production, reduce MMP $(\Delta \psi \mathrm{m})$ and consequently induce cell death $(11,12)$. Recently, we demonstrated that 2,4-dinitrophenol (DNP) as a mitochondrial uncoupler induces apoptosis in As4.1 cells via the loss of MMP $(\Delta \psi \mathrm{m})$ and alterations of GSH levels (13). In the present study, we evaluated the involvement of ROS and GSH in the carbonyl cyanide p(trifluoromethoxy) phenylhydrazone (FCCP)-induced death of As4.1 juxtaglomerular cells and examined the effects of 2-phenyl-1,2-benzisoselenazol-3(2H)-one (ebselen), Lbuthionine sulfoximine (BSO) and $\mathrm{N}$-acetylcysteine (NAC) on FCCP-treated As4.1 cells in relation to cell death, ROS and GSH.

\section{Materials and methods}

Cell culture. As4.1 cells were obtained from the American Type Culture Collection (ATCC, Manassas, VA) and maintained in a humidified incubator containing $5 \% \mathrm{CO}_{2}$ at $37^{\circ} \mathrm{C}$. As 4.1 cells were cultured in Dulbecco's modified Eagle's medium (DMEM) supplemented with $10 \%$ fetal bovine serum (FBS) and 1\% penicillin-streptomycin (Gibco-BRL, Grand Island, NY). Cells were routinely grown in $100-\mathrm{mm}$ plastic tissue culture dishes (Nunc, Roskilde, Denmark).

Reagents. DMEM, FBS, dimethylsulfoxide (DMSO), L-BSO, propidium iodide (PI), 3-(4,5-dimethylthiazol-2-yl)-2,5diphenyltetrazolium bromide (MTT), FCCP and ebselen were purchased from the Sigma-Aldrich Chemical Company (St. Louis, MO). FCCP was dissolved in ethanol at $200 \mathrm{mM}$ as a stock solution. BSO and ebselen were dissolved in water at $100 \mathrm{mM}$ as stock solutions. The non-toxic dietary glutathione precursor, NAC was obtained from Sigma and was dissolved in designated solution buffer $(500 \mathrm{mM}$ sodium bicarbonate) at $500 \mathrm{mM}$ as a stock solution. The control cells also contained the appropriated amounts of vehicles, which had no effect on cell death. All of the stock solutions were kept at $-20^{\circ} \mathrm{C}$.

Detection of intracellular ROS and GSH level. Intracellular ROS and GSH were detected using the probe $2^{\prime}, 7^{\prime}$ dichlorodihydrofluorescein diacetate $\left(\mathrm{H}_{2} \mathrm{DCFDA}\right.$; Ex/Em, $495 \mathrm{~nm} / 529 \mathrm{~nm}$ ) and 5-chlorometylfluorescein diacetate (CMFDA; Ex/Em, 522 nm/595 nm) (Invitrogen Molecular Probes, Eugene, OR) as previously described (14). Negative CMF staining (GSH depleted) cells were expressed as the percent of negative CMF cells. The CMF (excluding GSHdepleted cells) and ROS levels were expressed as mean fluorescence intensity (MFI), which was calculated with the CellQuest software (Becton-Dickinson).

Measurement of cellular SOD activity. The level of cellular SOD enzyme activity was measured using the SOD assay kit, WST (Fluka Co., Milwaukee, WI) as indicated by the manufacturer. Activities between $\mathrm{Mn}-\mathrm{SOD}$ and $\mathrm{Cu} / \mathrm{Zn}-\mathrm{SOD}$ were distinguished by differential sensitivity to $1 \mathrm{mM}$ potassium cyanide blocking the $\mathrm{Cu} / \mathrm{Zn}$-SOD activity (15). The value for the experimental group was converted to the percentage of the control group.

Measurement of cellular catalase activity. The level of cellular catalase enzyme activity was measured using the catalase assay kit from Sigma-Aldrich Chemical Company as indicated by the manufacturer. The value for the experimental group was converted to the percentage of control group.

Western blot analysis. Protein expression was evaluated using Western blot analysis, as previously described (16). In brief, $1 \times 10^{6}$ cells were incubated with $20 \mu \mathrm{M}$ of FCCP for 12-48 $\mathrm{h}$ with or without NAC. The cells were then washed in PBS and suspended in five volumes of lysis buffer $(20 \mathrm{mM}$ HEPES, pH 7.9, 20\% glycerol, $200 \mathrm{mM} \mathrm{KCl,} 0.5$ mM EDTA, $0.5 \%$ NP-40, $0.5 \mathrm{mM}$ DTT, $1 \%$ protease inhibitor cocktail). Lysates were collected and stored at $-20^{\circ} \mathrm{C}$ until further use. Supernatant protein concentrations were determined using the Bradford method. Supernatant samples containing $30 \mu \mathrm{g}$ total protein were resolved by SDS-PAGE gel depending on the target protein sizes, and were then transferred onto an Immobilon-P PVDF membranes (Millipore, MA) by electroblotting. The membranes were probed with antibodies against $\beta$-actin, PARP, Cu/Zn-SOD, and Mn-SOD (1:5000) (Santa Cruz Biotechnology, Santa Cruz, CA). Membranes were incubated with horseradish peroxidase-conjugated secondary antibodies. Blots were developed using an ECL kit (Amersham, Arlington Heights, IL).

Measurement of MMP $(\Delta \psi m)$. MMP $(\Delta \psi \mathrm{m})$ levels were measured using rhodamine 123 fluorescent dye (SigmaAldrich Chemical Company; Ex/Em, 485nm/535nm) as previously described (17). Rhodamine 123 staining intensity was determined by flow cytometry (Becton-Dickinson). An absence of rhodamine 123 from the cells indicated the loss of MMP $(\Delta \psi \mathrm{m})$ in cells. The MMP $(\Delta \psi \mathrm{m})$ levels in viable cells (excluding MMP $(\Delta \psi \mathrm{m})$ loss cells) were expressed as the MFI, which was calculated by the CellQuest software (Becton-Dickinson).

Annexin V-fluorescein isothiocyanate (FITC) staining for apoptotic detection. Apoptosis was determined by staining cells with annexin V-FITC (Invitrogen Corporation, Branford, CT; Ex/Em, $488 \mathrm{~nm} / 519 \mathrm{~nm}$ ). In brief, $1 \times 10^{6}$ cells were incubated with the designated doses of FCCP with or without NAC, BSO and ebselen for $48 \mathrm{~h}$. The cells were washed twice with cold PBS, and then resuspended in $500 \mu 1$ of binding buffer (10 mM HEPES/NaOH, pH 7.4, $140 \mathrm{mM}$ $\mathrm{NaCl}, 2.5 \mathrm{mM} \mathrm{CaCl}{ }_{2}$ ) at a concentration of $1 \times 10^{6}$ cells $/ \mathrm{ml}$. Annexin V-FITC (5 $\mu 1)$ was then added to these cells, which were analyzed with a FACStar flow cytometer (BectonDickinson).

Statistical analysis. The results represent the mean of at least three independent experiments (mean \pm SD). The data were analyzed using Instat software (GraphPad Prism4, San Diego, CA). The Student's t-test or one-way analysis of variance (ANOVA) with a post-hoc analysis using the Tukey's 
A

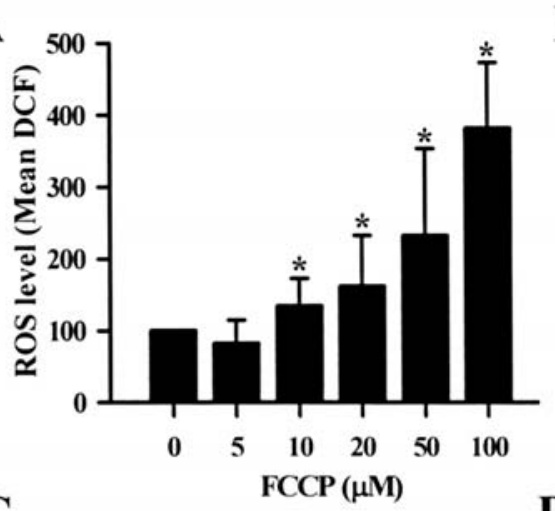

\section{C}

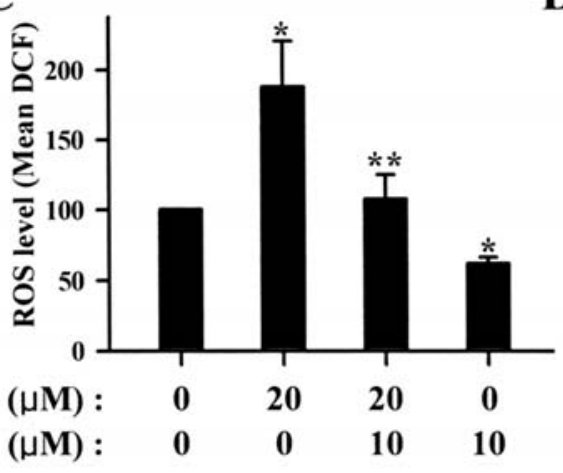

B

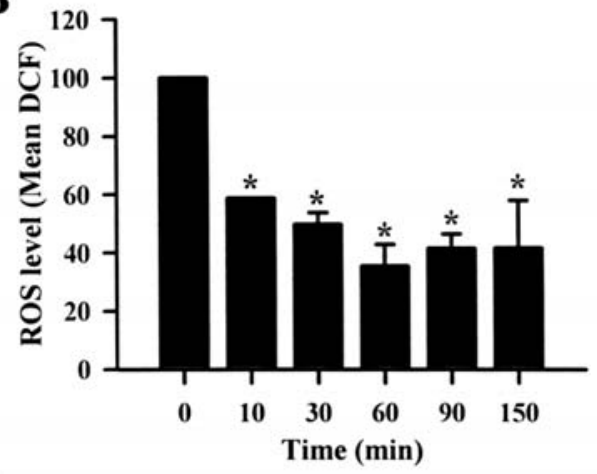

D

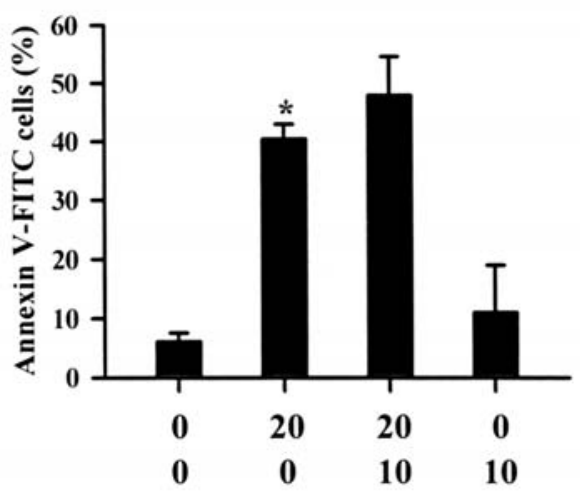

Figure 1. Effects of FCCP on ROS levels in As4.1 cells. (A and B) The graphs show intracellular ROS levels in 5-100 $\mu$ M FCCP-treated cells at 48 h (A) and in $20 \mu \mathrm{M}$ FCCP-treated cells for $10-150 \mathrm{~min}$ (B). (C) The graph shows intracellular ROS levels in FCCP-treated cells at $48 \mathrm{~h}$ following pre-treatment with $10 \mu \mathrm{M}$ ebselen for $30 \mathrm{~min}$. (D) The graph shows the percent of annexin V-FITC cells in As4.1 cell treated with FCCP and/or ebselen. ${ }^{*} \mathrm{P}<0.05$ compared with the control. ${ }^{* *} \mathrm{P}<0.05$ compared with cells treated only with FCCP.

multiple comparison test for parametric data. Statistical significance was defined as $\mathrm{p}<0.05$.

\section{Results}

Effects of FCCP on ROS level in As4.1 cells. We have previously observed that FCCP inhibited the growth of As4.1 cells with an $\mathrm{IC}_{50}$ of approximately $10 \mu \mathrm{M}$ FCCP and induced apoptosis at $48 \mathrm{~h}$ (18). We first screened As4.1 cells with a wide range FCCP concentrations and chose the optimal doses $(5-100 \mu \mathrm{M})$ and incubation times $(10-150$ min or $48 \mathrm{~h})$ for further experiments. As shown in Fig. 1A, increases in ROS level were detected in a dose-dependent manner at $48 \mathrm{~h}$. The level of ROS in As4.1 cells treated with $100 \mu \mathrm{M}$ FCCP was approximately $4 \mathrm{x}$ higher than that of the control cells (Fig. 1A). Treatment with $20 \mu \mathrm{M}$ FCCP, considered to be a suitable dose to differentiate the level of apoptosis, significantly decreased ROS levels at the early times points of 10-150 min (Fig. 1B).

To test whether ROS act as signaling molecules to induce cell death in FCCP-treated As4.1 cells, cells were treated with ebselen for 30 min prior to FCCP exposure. Pretreatment with $10 \mu \mathrm{M}$ ebselen efficiently reduced ROS levels in $20 \mu \mathrm{M}$ FCCP treated-and untreated-cells at early time points (data not shown) and at $48 \mathrm{~h}$ (Fig. 1C). However, ebselen did not protect As4.1 cells against FCCP insults, as shown by the annexin V-positive staining of As4.1 cells (Fig. 1D). Collectively, FCCP reduced ROS levels for the early time phases, and finally increased the level at the late time phase of $48 \mathrm{~h}$. In addition, FCCP induced apoptosis in As4.1 cells, which was not prevented by ebselen.

Effects of FCCP on SOD and catalase in As4.1 cells. Because FCCP increased ROS levels at $48 \mathrm{~h}$, we attempted to evaluate whether FCCP affects these antioxidant enzymes in As4.1 cells. Treatment with $20 \mu \mathrm{M}$ FCCP significantly inhibited the Mn-SOD activity in a time-dependent manner, while the activity of $\mathrm{Cu} / \mathrm{Zn}$-SOD was not changed for $48 \mathrm{~h}$ (Fig. 2A). In addition, treatment with FCCP enhanced the activity of catalase in As4.1 cells for $12 \mathrm{~h}$. After $12 \mathrm{~h}$, catalase activity was diminished (Fig. 2A). Treatment with FCCP also down-regulated Mn-SOD protein expression and did not change $\mathrm{Cu} / \mathrm{Zn}$-SOD protein expression during the tested time (Fig. 2B).

Effects of FCCP on the intracellular GSH levels in As4.1 cells. Next, we analyzed the changes of GSH levels in As4.1 cells using the CMF dye. The M1 regions in Fig. 3A demonstrate the depletion of GSH content in As4.1 cells. FCCP significantly elevated the numbers of cells in the M1 region at $48 \mathrm{~h}$ in a dose-dependent manner, indicating that FCCP induced a dose-dependent depletion of the intracellular GSH contents in As4.1 cells. Treatment with $20 \mu \mathrm{M}$ FCCP for short time periods, decreased GSH levels (mean CMF fluorescence) within $10 \mathrm{~min}$, and the decrease in GSH levels remained for the tested time of $150 \mathrm{~min}$ (Fig. 3B). 
A

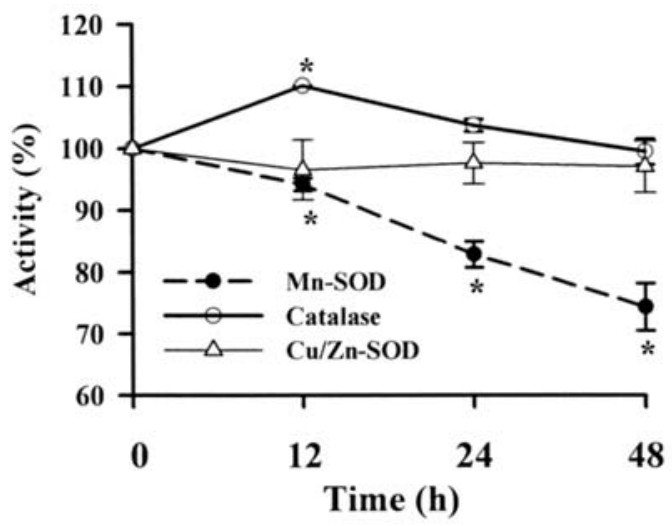

B

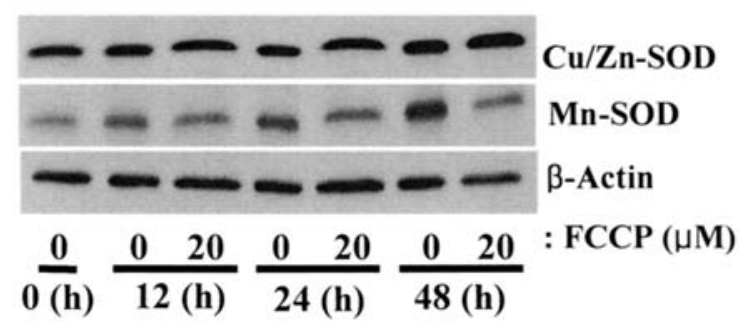

Figure 2. Effects of FCCP on SOD and catalase in As4.1 cells. (A) The graph shows the activities of $\mathrm{Cu} / \mathrm{Zn}-\mathrm{SOD}, \mathrm{Mn}$-SOD and catalase. Results shown are the means of three independent experiments. ${ }^{*} \mathrm{P}<0.05$ compared with the control group. (B) Protein extracts were separated by SDS-PAGE gel, transferred onto the PVDF membrane and immunoblotted with the indicated antibodies, $\mathrm{Cu} / \mathrm{Zn}-\mathrm{SOD}, \mathrm{Mn}-\mathrm{SOD}$ and $\beta$-actin.
Effects of BSO on GSH level, ROS level, and apoptosis in FCCP-treated As4.1 cells. To verify the possibility that a decrease in GSH levls is relevant to FCCP-induced As4.1 cell death, the reduction of GSH levels was induced by pretreatment with $20 \mu \mathrm{M}$ BSO (a GSH synthesis inhibitor) (19). BSO diminished the intracellular GSH level in FCCP-treated As4.1 cells and control cells (Fig. 3C). Coincidentally, BSO intensified FCCP-induced apoptosis in As4.1 cells whereas this agent alone did not induce apoptosis in As4.1 control cells (Fig. 3D). Concerning the intracellular ROS levels, BSO strongly exaggerated intracellular ROS level in FCCPtreated As4.1 cells (Fig. 3E). BSO alone increased intracellular ROS levels as well (Fig. 3E).

Effects of NAC on GSH levels, ROS levels and apoptosis in FCCP-treated As4.1 cells. We investigated whether ROS and GSH levels in FCCP-treated As4.1 cells were altered by a well known antioxidant, NAC. Pre-treatment of As4.1 cells with $2 \mathrm{mM}$ NAC for $30 \mathrm{~min}$ prevented FCCP-mediated GSH reduction at early time points (30-120 min) (Fig. 4A). Intracellular GSH contents were slightly increased in NACtreated control cells (Fig. 4A). However, the increase in GSH did not appear to be statistically significant. Treatment with $2 \mathrm{mM}$ NAC significantly prevented the GSH depletion level in FCCP-treated As4.1 cells at $48 \mathrm{~h}$ (Fig. 4B) and decreased the ROS (Fig. 4C). NAC alone, did not affect GSH and ROS levels in control cells (data not shown). NAC restored $\mathrm{Mn}-\mathrm{SOD}$ activity and its expression was reduced by FCCP at $48 \mathrm{~h}$ (Fig. 4D and E).

Next, we examined whether NAC inhibited FCCP-induced apoptosis. As shown in Fig. 5A, NAC rescued some cells
A
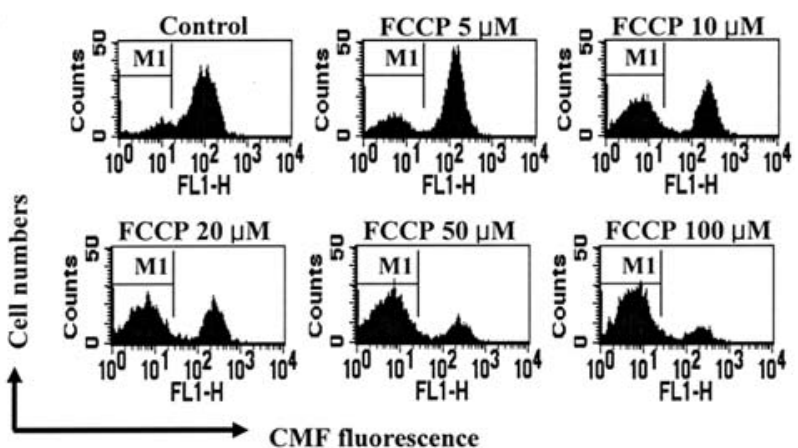

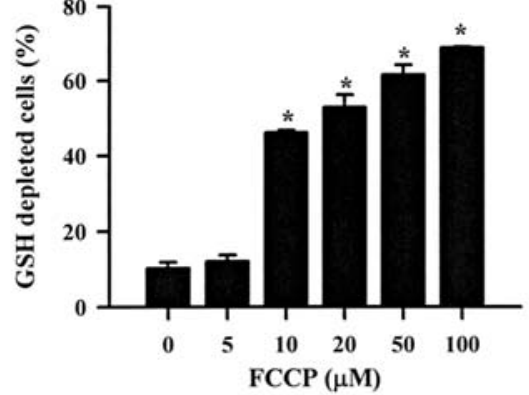

D

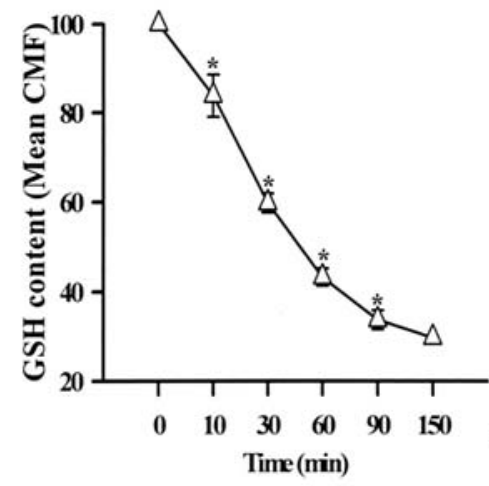

C
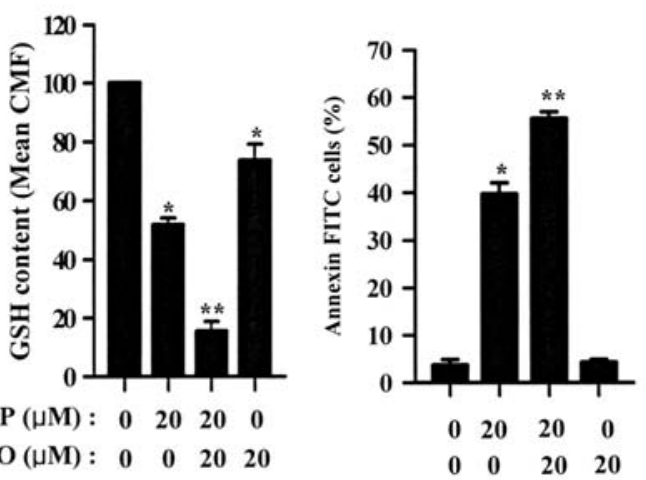

$\mathbf{E}$

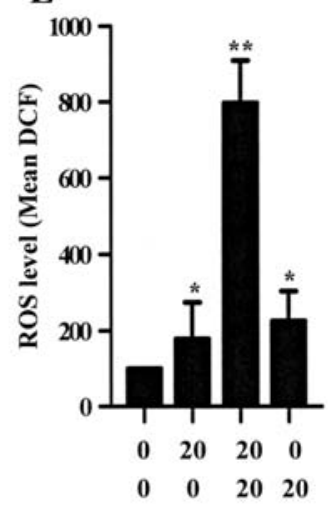

Figure 3. Effects of FCCP and/or BSO on intracellular GSH, ROS and apoptosis in As4.1 cells. (A) The M1 region indicates GSH-depleted (CMF negative) cells. The graph shows the percent of M1 region cells in FCCP-treated As4.1 cells at $48 \mathrm{~h}$. (B) The graph shows the levels of mean CMF fluorescence in As4.1 cells. (C-E) Graphs show intracellular GSH contents (C), annexin V FITC-stained cells (D) and intracellular ROS level (E). ${ }^{*} \mathrm{P}<0.05$ compared with the control group. ${ }^{* *} \mathrm{P}<0.05$ compared with the FCCP only-treated cells. 


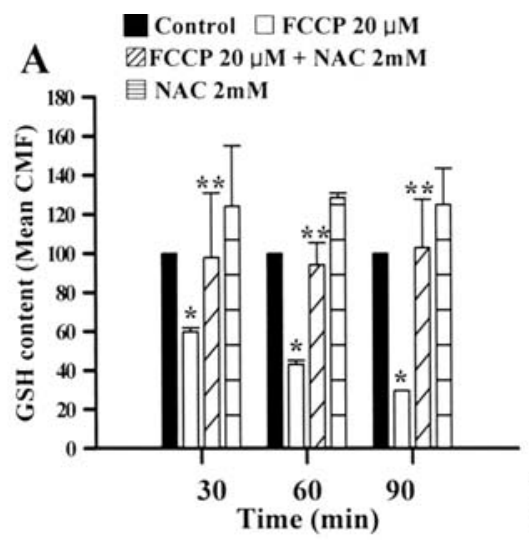

B

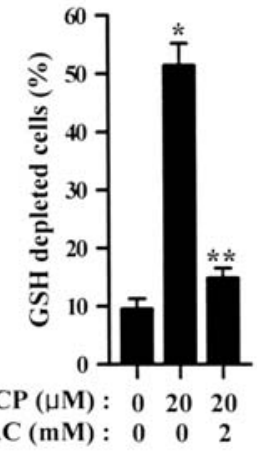

C

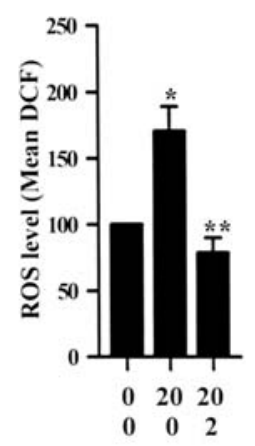

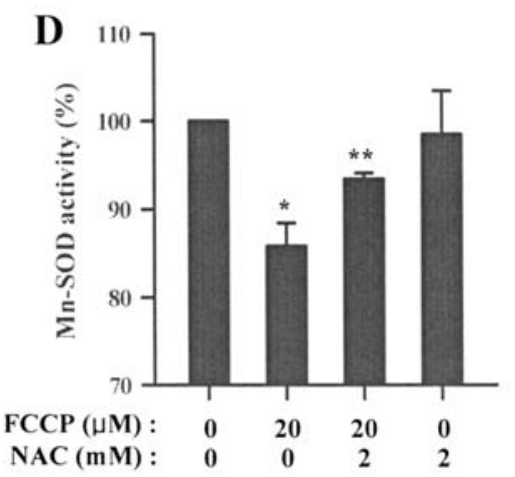

E

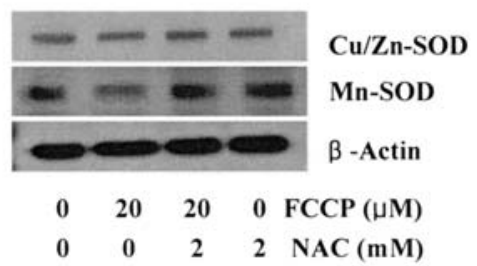

Figure 4. Effects of NAC on GSH, ROS and SOD activity in FCCP-treated As4.1 cells. Exponentially growing cells were pretreated with NAC for 30 min and exposed to $20 \mu \mathrm{M}$ FCCP for the indicated times or $48 \mathrm{~h}$. (A-D) The graphs show intracellular GSH levels (A), percent of GSH depleted cells (B), intracellular ROS levels (C) and Mn-SOD activity (D). (E) Immnunoblot analysis of Cu/Zn-SOD and Mn-SOD protein. " $\mathrm{P}<0.05$ compared with the control group; ${ }^{* *} \mathrm{P}<0.05$ compared with the FCCP only-treated cells.

A

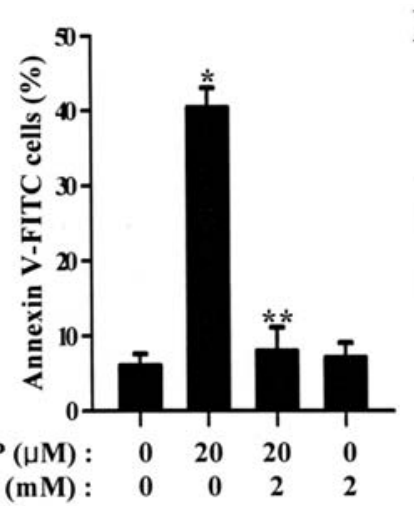

B

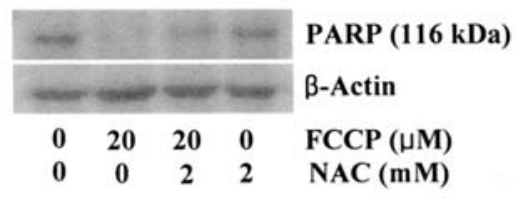

Control $\square$ FCCP $20 \mu \mathrm{M}$

C

D

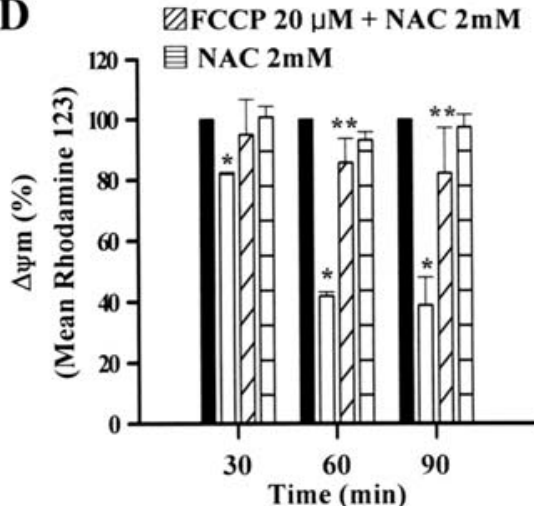

Figure 5. Effects of NAC on apoptosis and MMP $(\Delta \psi \mathrm{m})$ in FCCP-treated As4.1 cells. Following treatment with 2 mM NAC for 30 min, cells were treated with $20 \mu \mathrm{M}$ FCCP for the designated times or $48 \mathrm{~h}$. (A) Percent of annexin V-positive cells. (B) Immnunoblot detection of PARP. (C) Percent of rhodamine 123 negative staining [MMP $(\Delta \psi \mathrm{m})$ loss] cells. (D) Levels of mean rhodamine 123 in cells except MMP $(\Delta \psi \mathrm{m})$ loss cells. ${ }^{*} \mathrm{P}<0.05$ compared with the control group; ${ }^{* *} \mathrm{P}<0.05$ compared with the FCCP only-treated cells. 
from FCCP insults, as assessed by the percentage of annexin $\mathrm{V}$ positive cells. In addition, NAC partially prevented the cleavage of PARP (a hallmark of apoptosis) in FCCP-treated cells (Fig. 5B). NAC also efficiently prevented the loss of MMP $(\Delta \psi \mathrm{m})$ in FCCP-treated As4.1 cells at $48 \mathrm{~h}$ (Fig. 5C). At the early time points (30-120 min), FCCP significantly reduced the MMP $(\Delta \psi \mathrm{m})$ level and NAC attenuated the decreased level (Fig. 5D).

\section{Discussion}

In the present study, we focused on the roles of ROS and GSH in FCCP-induced As4.1 cell death. The scheme for FCCP-induced As4.1 cell death according to our data is shown in Fig. 6. ROS and GSH levels were significantly decreased at the early time points. However, FCCP increased intracellular ROS level at $48 \mathrm{~h}$. This result indicates that ROS levels are dependent on incubation times of FCCP and raises the possibility that prolonged incubation with FCCP induces mitochondrial membrane damage. In fact, we observed that FCCP induced the loss of MMP $(\Delta \psi \mathrm{m})$ in As4.1 cell. When determining whether a ROS scavenger prevented FCCPinduced cell death, ebselen caused the reduction of ROS levels in FCCP-treated As4.1 cells, but it did not decrease apoptosis levels in these cells. We have also recently reported that ROS scavengers did not prevent apoptosis in FCCP-treated Calu-6 lung cancer cells or DNP-treated As4.1 cells $(13,20)$. Furthermore, BSO strongly increased ROS levels in FCCP-treated As4.1 cells, but it mildly enhanced apoptosis in FCCP-treated cells. BSO alone increased ROS levels to a similar level of FCCP-treated cells without cell death. In contrast, another antioxidant of NAC induced parallel decreases in ROS level and apoptosis in FCCPtreated As4.1 cells. Taken together, these results suggest that intracellular ROS levels are not closely, but to some extent related to FCCP-induced cell death in As4.1 cells.

The high level of ROS in FCCP-treated cells at $48 \mathrm{~h}$ was likely to be from the decreased activity of SOD, especially Mn-SOD activity as well as mitochondrial membrane damage. The activity of Mn-SOD was reduced in FCCP-treated As4.1 cells at $\sim 12-48 \mathrm{~h}$. This decrease seemed to down-regulate the dismutation of the $\mathrm{O}_{2}^{-}$generated from mitochondria into $\mathrm{H}_{2} \mathrm{O}_{2}$, resulting in accumulation of ROS in the cells. Interestingly, an increased catalase activity was observed in FCCP-treated As 4.1 cells at $12 \mathrm{~h}$ and the augmented catalase activity decreased between 12-48 h. Kuruvilla et al showed that FCCP down-regulated the gene expression associated with antioxidant enzymes in a human rhabdomyosarcoma cell line (21). Conclusively, these results indicate that intracellular ROS level in FCCP-treated cells is regulated by various redox-related proteins including Mn-SOD and catalase as well as mitochondrial damage.

Intracellular GSH levels have a decisive role in anticancer drug-induced apoptosis, as indicated by the fact that apoptotic effects are inversely comparative to GSH levels $(22,23)$. The reduction of GSH levels in FCCP-treated Calu-6 lung cells has a decisive effect on cell death (20). Likewise, decreased GSH levels and GSH depletion were observed in FCCPtreated As4.1 cells. This finding suggests that FCCP plays a role as a GSH depletor itself in As4.1 cells. Although we

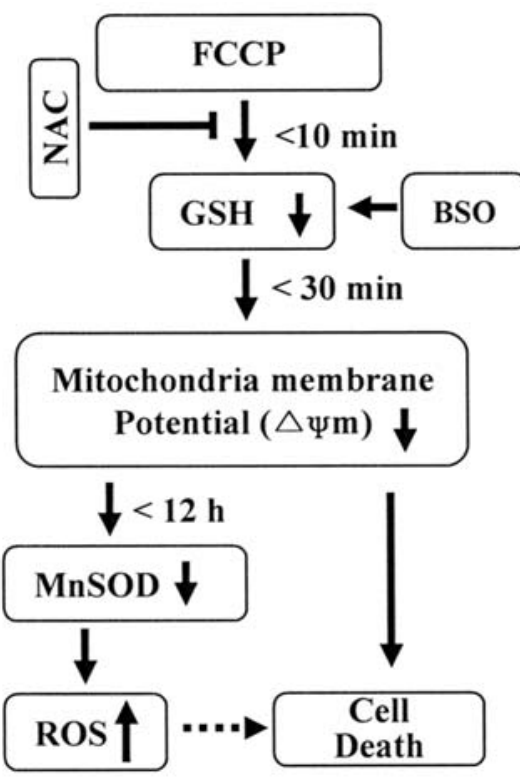

Figure 6. The scheme for FCCP-induced As4.1 cell death.

cannot exactly explain how FCCP decreased GSH, it is likely that FCCP directly interacts with GSH since FCCP decreased GSH content within $10 \mathrm{~min}$. In addition, inhibition of GSH synthesis by BSO significantly aggravated the reduction of GSH content and cell death in FCCP-treated As4.1 cells. NAC obviously increased GSH levels at the early time points and inhibited depletion of GSH in FCCP-treated As4.1 cells. NAC also prevented apoptosis and PARP cleavage in FCCPtreated As4.1 cells. These results are consistent with other reports that intracellular GSH is rapidly decreased before the commencement of cell death in response to various insults $(20,24,25)$. Notably, BSO alone decreased the intracellular GSH level without cell death in As4.1 cells. These results suggest that a simple decrease in GSH levels is necessary, but not sufficient to trigger apoptosis.

GSH depletion has been shown to directly modulate both formation of the permeability transition pore and cell death (26-28). According to our results, a decrease in GSH level and MMP $(\Delta \psi \mathrm{m})$ were observed in FCCP-treated As4.1 cells at early time points. NAC increased both GSH level and MMP $(\Delta \psi \mathrm{m})$ levels in FCCP-treated cells. Interestingly, the decreased GSH level by FCCP at the early time points was higher than the MMP $(\Delta \psi \mathrm{m})$ reduction levels. Probably, FCCP primarily decreases intracellular GSH and then induces mitochondrial dysfunction to progress to subsequent steps, such as loss of MMP $(\Delta \psi \mathrm{m})$ and generation of ROS.

Taken together, our results suggest that compared to ROS levels, intracellular GSH levels are more closely linked to FCCP-induced apoptosis in As4.1 juxtaglomerular cells.

\section{Acknowledgements}

This work was supported by a grant from the Ministry of Science and Technology (MoST)/Korea Science and Engineering Foundation (KOSEF) through the Diabetes Research Center at Chonbuk National University (20100029497) and the National Research Foundation of Korea 
Grant funded by the Korean Government (MEST) (20100021808).

\section{References}

1. Robertson PW, Klidjian A, Harding LK Walters G, Lee MR and Robb-Smith AH: Hypertension due to a renin-secreting renal tumour. Am J Med 43: 963-976, 1967.

2. Sigmund CD, Okuyama K, Ingelfinger J, Jones CA, Mullins JJ, Kane C, Kim U, Wu CZ, Kenny L, Rustum Y et al: Isolation and characterization of renin-expressing cell lines from transgenic mice containing a renin-promoter viral oncogene fusion construct. J Biol Chem 265: 19916-19922, 1990.

3. Markey RB and MacLennan GT: Juxtaglomerular cell tumor of the kidney. J Urol 175: 730, 2006.

4. Baran CP, Zeigler MM, Tridandapani S and Marsh CB: The role of ROS and RNS in regulating life and death of blood monocytes. Cur Pharm Des 10: 855-866, 2004.

5. Valko M, Rhodes CJ, Moncol J, Izakovic M and Mazur M: Free radicals, metals and antioxidants in oxidative stress-induced cancer. Chem Biol Interact 160: 1-40, 2006.

6. Poot M, Teubert H, Rabinovitch PS and Kavanagh TJ: De novo synthesis of glutathione is required for both entry into and progression through the cell cycle. J Cell Physiol 163: 555-560, 1995.

7. Lauterburg BH: Analgesics and glutathione. Am J Ther 9: 225-233, 2002

8. Wu G, Fang YZ, Yang S, Lupton JR and Turner ND: Glutathione metabolism and its implications for health. J Nutr 134: 489-492, 2004.

9. Watson RW, Rotstein OD, Jimenez M, Parodo J and Marshall JC: Augmented intracellular glutathione inhibits Fas-triggered apoptosis of activated human neutrophils. Blood 89: 4175-4181, 1997.

10. Armstrong JS: Mitochondrial medicine: pharmacological targeting of mitochondria in disease. Br J Pharm 151: 1154-1165, 2007.

11. Daouphars M, Koufany M, Benani A, Marchal S, Merlin JL, Netter P and Jouzeau JY: Uncoupling of oxidative phosphorylation and Smac/DIABLO release are not sufficient to account for induction of apoptosis by sulindac sulfide in human colorectal cancer cells. Int J Oncol 26: 1069-1077, 2005.

12. Dispersyn G, Nuydens R, Connors R, Borgers M and Geerts H: $\mathrm{Bcl}-2$ protects against FCCP-induced apoptosis and mitochondrial membrane potential depolarization in PC12 cells Biochim Biophys Acta 1428: 357-371, 1999.

13. Han YH, Kim SZ, Kim SH and Park WH: 2,4-Dinitrophenol induces apoptosis in As4.1 juxtaglomerular cells through rapid depletion of GSH. Cell Biol Int 32: 1536-1545, 2008.

14. Han YW, Kim SZ, Kim SH and Park WH: The changes of intracellular $\mathrm{H}_{2} \mathrm{O}_{2}$ are an important factor maintaining mitochondria membrane potential of antimycin A-treated As4.1 juxtaglomerular cells. Biochem Pharmacol 73: 863-872, 2007.
15. Rigo A, Stevanato R and Viglino P: Competitive inhibition of $\mathrm{Cu}, \mathrm{Zn}$ superoxide dismutase by monovalent anions. Biochem Biophys Res Commun 79: 776-783, 1977.

16. Han YH, Kim SW, Kim SH, Kim SZ and Park WH: 2,4dinitrophenol induces G1 phase arrest and apoptosis in human pulmonary adenocarcinoma Calu-6 cells. Toxicol In Vitro 22: 659-670, 2008

17. Han YH, Kim SZ, Kim SH and Park WH: Arsenic trioxide inhibits growth of As4.1 juxtaglomerular cells via cell cycle arrest and caspase-independent apoptosis. Am J Physiol Renal Physiol 293: F511-F520, 2007.

18. Han YH, Yang YM and Park WH: Carbonyl cyanide p(trifluoromethoxy) phenylhydroazone induces caspaseindependent apoptosis in As4.1 juxtaglomerular cells. Anticancer Res 30: 2863-2868, 2010.

19. Bailey HH: L-S,R-buthionine sulfoximine: historical development and clinical issues. Chem Biol Interact 111-112: 239-254, 1998 .

20. Han YH, Kim SH, Kim SZ and Park WH: Carbonyl cyanide p(trifluoromethoxy) phenylhydrazone (FCCP) as an $\mathrm{O}_{2}\left(*_{-}\right)$ generator induces apoptosis via the depletion of intracellular GSH contents in Calu-6 cells. Lung Cancer 63: 201-209, 2009.

21. Kuruvilla S, Qualls CW Jr, Tyler RD, Witherspoon SM, Benavides GR, Yoon LW, Dold K, Brown RH, Sangiah S, Morgan KT: Effects of minimally toxic levels of carbonyl cyanide P-(trifluoromethoxy) phenylhydrazone (FCCP), elucidated through differential gene expression with biochemical and morphological correlations. Toxicol Sci 73: 348-61, 2003

22. Estrela JM, Ortega A and Obrador E: Glutathione in cancer biology and therapy. Crit Rev Clin Lab Sci 43: 143-181, 2006.

23. Higuchi Y: Glutathione depletion-induced chromosomal DNA fragmentation associated with apoptosis and necrosis. J Cell Mol Med 8: 455-464, 2004.

24. Biroccio A, Benassi B, Fiorentino F and Zupi G: Glutathione depletion induced by c-myc downregulation triggers apoptosis on treatment with alkylating agents. Neoplasia 6: 195-206, 2004.

25. Honda T, Coppola S, Ghibelli L, Cho SH, Kagawa S, Spurgers KB, Brisbay SM, Roth JA, Meyn RE, Fang B and McDonnell TJ: GSH depletion enhances adenoviral bax-induced apoptosis in lung cancer cells. Cancer Gene Ther 11: 249-255, 2004.

26. Franco R and Cidlowski JA: SLCO/OATP-like transport of glutathione in FasL-induced apoptosis: glutathione efflux is coupled to an organic anion exchange and is necessary for the progression of the execution phase of apoptosis. J Biol Chem 281: 29542-29547, 2006.

27. Armstrong JS and Jones DP: Glutathione depletion enforces the mitochondrial permeability transition and causes cell death in Bcl-2 overexpressing HL60 cells. FASEB J 16: 1263-1265, 2002.

28. Varghese J, Khandre NS and Sarin A: Caspase-3 activation is an early event and initiates apoptotic damage in a human leukemia cell line. Apoptosis 8: 363-370, 2003. 